Absolutely unafraid it waddled through our legs and over our toes. When approached the bird neither flinched nor shied away but hopped through the arch created by my leg as I knelt. At first I thought this might be a young or injured bird and hence flightless. However, after five minutes of wandering through the gathering crowd it flew without difficulty into an aspen, then over the top of the nature centre. I never saw the bird again that summer.

Birds like the Gray Jay and Clark's Nutcracker are often unafraid of humans and are rather bold. Still they exhibit a degree of caution when robbing food from picnic tables or scavenging in trash cans. A foray into the bird's "safety zone" elicits an avoidance response, one the cowbird did not show. It acted as if it knew it was unthreatened by people, and indeed no one was about to cause it harm. The confrontation would have been different (and probably fatal for the cowbird) had a fox or domestic dog or cat been present. The survival value of such nonchalant behaviour must be very low.

Even without attempting to answer the questions posed by this unusual bird behaviour, I felt that the observation was of intrinsic value. I decided it was a time to say very little. To appreciate nature, it does not always take a script-perfect presentation, audio-visual aids, or even an attempted explanation.

Perhaps a collection of first-hand experiences similar to this cowbird observation might foster a better understanding of nature on the part of the ordinary person. The resulting appreciation and concern could influence people when they are asked for their opinion, or to allocate funds or cast a ballot on an environmental issue. It could start people on the road to being "tuned in and turned on" to natural environments.

\section{MAGPIE ATTEMPTS TO CAPTURE MOUSE}

WAYNE C. HARRIS, Box 414, Raymore, Saskatchewan. SOA 3JO

On 3 January 1982, while driving along a grid road northwest of Maidstone, Saskatchewan, Sheila Lamont and I watched a Black-billed Magpie flying over a field towards the road. As it crossed the road it suddenly plunged into the ditch out of our view behind an approach. After two or three seconds it re-appeared carrying a dark object in its bill which it dropped after flying a few feet. The magpie plunged back into the ditch, retrieved the object and again dropped it. It appeared as if it was going to plunge after the object once more but was frightened away by our approaching vehicle.

Curious as to what type of "garbage" the magpie had been trying to carry away I stopped to investigate. To my surprise I saw nothing in the ditch. Closer examination found tracks which revealed that a mouse had come out of a small tunnel and was running along the ditch when the magpie captured it. The mouse tracks re-appeared about four feet along in the ditch and again disappeared only to re-appear again. The mouse tracks then led to a tunnel where it had apparently burrowed back under the safety of the snow.

The tracks appeared to be of a Deer Mouse (Peromyscus sp.) but I am not certain of this identification.

Although the Black-billed Magpie is known to be a very opportunistic feeder, I did not expect one to attempt to capture live prey the size of an adult mouse. 